\title{
LA ESCUELA UNIVERSITARIA DE LAS CIENCIAS DE LA SALUD, DEL VALLE DE SULA
}

\section{University school of health sciences, Sula Valley}

En nombre del Consejo Editorial de la Revista Científica de la Escuela Universitaria de las Ciencias de la Salud (EUCS), de la Universidad Nacional Autónoma de Honduras en el Valle de Sula, me enorgullece presentarles el quinto número de nuestra querida revista. Como recordarán, hemos dedicado las ediciones previas a cada carrera de la EUCS, según orden cronológico de su creación; el primer número fue alusivo a la carrera de Enfermería que fue creada el año 1979, el segundo a Odontología creada en el año 2000, el tercero a Medicina que fue creada el año 2003 (sin embargo comenzó a funcionar completamente el año 2006) y el cuarto a los Posgrados de medicina que iniciaron a desarrollarse en los diferentes Hospitales de San Pedro Sula, el año 2006 (Pediatría y Ginecoobstetricia).

En mayo de 2006 surgió la idea de formar la Escuela Universitaria de las Ciencias de la Salud, por lo que dos meses después se realizó un foro con autoridades de la Secretaría de Salud y miembros de los Colegios Profesionales de Ciencias de la Salud y Ciencias Sociales; en septiembre del mismo año, los miembros de la Comisión de Transición (CT) Dr. Jorge Haddad Quiñones presidente y la Dra. Norma Martin de Reyes, también miembro de dicha Comisión, en compañía de la Dra. Rutilia Calderón Vicerrectora Académica, consolidaron el Grupo Gestor de la EUCS. En febrero de 2008 se entregó el documento del proyecto al MTE. Carlos Alberto Pineda Fernández, Director de la UNAH-VS, quien lo envió a la CT para su aprobación. (1) En septiembre del mismo año mediante "acuerdo $\mathrm{N}^{\circ}$ 348-A-2008" se aprueba la creación de la Escuela Universitaria de Ciencias de la Salud (EUCS), ${ }^{(2-3)}$ siendo su primer director el Dr. Francisco José Herrera Alvarado quien fungió en el cargo, hasta el año 2013.
La EUCS fue creada para contribuir a dar respuesta a los principales problemas de salud de la región nor-occidental mediante la gestión del conocimiento, a través de 4 ejes curriculares transversales: a) Promoción de la salud, b) Investigación interdisciplinaria de problemas prioritarios de salud, c) Valores; ética y bioética, d) Gestión en salud.

En la actualidad, está a su cargo, el Dr. José Raúl Arita Chávez quien es el director desde el año 2014. Se cuenta con tres carreras de pregrado; enfermería, odontología y medicina. En cada carrera existe un Jefe, (enfermería: Lic. Ana María López Luna, odontología: Dr. Ángel Leobardo Vallejo Villatoro) quienes se encargan de los asuntos relacionados con los docentes y un coordinador de carrera que atiende a los estudiantes (enfermería: Lic. María Nubia Monje, odontología: Dra. Ericka Jannette Grisales y medicina: Dr. José Pastor Laínez Macis). En medicina, existen tres departamentos, cada uno con su propio jefe: Ciencias básicas de la salud, Medicina clínico integral y Salud pública (Dr. Roberto Pineda Leiva, Dr. Marco Antonio Molina Soto y Dr. Manuel Bonilla Cervantes respectivamente). Además se brindan dos carreras de posgrado que son la especialidad de pediatría coordinado por el Dr. Gabriel Enrique Bennett y ginecoobstetricia coordinado por la Dra. Fresia María Alvarado Gámez.

Se está trabajando arduamente en los cuatro ejes curriculares transversales planteados, formando profesionales capaces de resolver los problemas de la población en las diferentes áreas de la salud, así mismo se realizan actividades de vinculación con la sociedad y se están realizando múltiples investigaciones individuales e interdisciplinarias. Muchos de los estudiantes y docentes de la EUCS han 
presentado sus resultados de investigación en eventos científicos locales, nacionales e internacionales. Pero no todo termina ahí, se han elaborado y publicado artículos científicos en revistas nacionales e internacionales. El año 2011 se realizaron los primeros esfuerzos por contar con una revista, elaborando un número. A partir del año 2014, se ha publicado ininterrumpidamente La Revista Científica de la EUCS, órgano oficial de difusión de trabajos científicos relacionados con la clínica, práctica e investigación en el área de la salud. La Revista es de periodicidad semestral, estimula a estudiantes y docentes para que las investigaciones realizadas sean de calidad y puedan convertirse en artículos científicos publicados.

Dra. Tania Soledad Licona Rivera.

Directora de la Revista Científica EUCS.

Dirigir correspondencia a: tania.licona@unah.edu.hn

Recibido: 24 de agosto $2016 \quad$ Aprobado: 25 de agosto 2016

\section{BIBLIOGRAFÍA}

1. Moran Elba. Universidad Nacional Autónoma de Honduras en el Valle de Sula. [power point]. San Pedro Sula: Docplayer; 73 diapositivas.

Disponible en: http://docplayer.es/27354 18-Universidad-nacional-autonoma-de -honduras -en-el-valle-de-sula.html.

2. Amaya de Blair MJ, Suazo Camilla ER. Historia de enfermería en la Universidad
Nacional Autónoma de Honduras-Valle de Sula. Rev. Cient. Esc. Univ. Cienc. Salud. 2014;1(1): 5-9.

3. Arita Chávez JR. Historia de la carrera de medicina en la Universidad Nacional Autónoma de Honduras en el Valle de Sula. Rev. Cient. Esc. Univ. Cienc. Salud. 2015; 2(1): 5-12. 